\title{
Two case reports of the successful eradication of new isolates of Burkholderia cepacia complex in children with cystic fibrosis
}

\author{
H. Kitt ${ }^{1}$, W. Lenney ${ }^{1}$ and F. J. Gilchrist ${ }^{1,2^{*}}$
}

\begin{abstract}
Background: Chronic infection with Burkholderia cepacia complex (BCC) has a detrimental effect on morbidity and mortality for patients with cystic fibrosis (CF). It is therefore logical to attempt to eradicate new isolates however there is a paucity of information to guide treatment. We report the successful eradication of new isolates of BCC in two children with CF.

Case presentation: Burkholderia cepacia was successfully eradicated in a 14 year old boy with CF and Burkholderia gladioli was successfully eradicated in a six year old girl with CF. In both children two weeks of intravenous (IV) tobramycin, ceftazidime and temocillin were used followed by three months of inhaled tobramycin.

Bronchoalveolar lavage samples taken during flexible bronchoscopy were used prior to treatment to exclude spontaneous clearance as well as after treatment to confirm eradication.

Conclusions: New isolates of BCC can be successfully eradicated in children with CF. More research is urgently required in this area to identify the best treatment regimen for BCC eradication.
\end{abstract}

Keywords: Burkholderia cepacia complex, Cystic fibrosis, Eradication, Paediatrics

\section{Background}

Cystic fibrosis (CF) is the commonest life shortening, inherited disease in the Caucasian population. It is characterised by recurrent lower respiratory infections, inflammation and lung damage. Burkholderia cepacia complex (BCC) refers to a group of at least 17 closely related bacterial species (formerly called genomovars) that can cause pulmonary infection in patients with cystic fibrosis (CF) [1-3]. These Gram-negative organisms are inherently resistant to Colistin and can survive for prolonged periods in moist environments such as water and soil [1]. In patients with $C F$, new BCC infection can clear spontaneously or require eradication with a combination of antibiotics. If new infection is not cleared, chronic infection develops. Chronic BCC infection is associated

\footnotetext{
* Correspondence: francis.gilchrist@uhns.nhs.uk

${ }^{1}$ Royal Stoke University Hospital, Stoke on Trent ST4 6QG, UK

${ }^{2}$ Academic Department of Child Health, Royal Stoke University Hospital,

Newcastle Road, Stoke on Trent ST4 6QG, UK
}

with a more rapid decline in lung function [4], increased requirements for intravenous antibiotics [5], increased outpatient attendance and increased mortality [6]. Patient to patient spread of epidemic strains of Burkholderia cenocepacia (such as ET12) was identified at a number of CF centres in the early 1990's [7]. This had a catastrophic effect on the CF population due to its association with Cepacia Syndrome. This is an acute, necrotising pneumonia with an almost universal fatal outcome [8]. The presence of Burkholderia cenocepacia remains a contraindication to lung transplantation at most $\mathrm{CF}$ transplantation centres due its association with poor outcomes [9]. The widespread segregation of CF clinics has been successful in reducing the overall prevalence of chronic BCC infection in the UK to $3 \%$ [10]. It is predominantly seen in adult patients [10]. The success of segregation means that most new BCC infections are now acquired from the environment rather than from other patients [11]. 
Despite a wealth of knowledge on the adverse longterm effects of BCC infection, there is lack of reliable evidence on which to base management decisions for $\mathrm{CF}$ patients with new or chronic BCC infection $[12,13]$. An in-vitro study suggest that triple-antibiotic combinations are more likely than double and single antibiotic combinations to be bactericidal against BCC [14]. Despite this, a Cochrane Systematic Review failed to identify a single randomised study investigating $\mathrm{BCC}$ eradication and concluded that "without further comprehensive studies it is difficult to draw conclusions about a safe and effective management strategy for BCC eradication in CF" [13]. A review of practice in UK CF Centres revealed that despite this lack of evidence, most attempt to eradicate new isolates of BCC. The treatment regimens vary widely and reported success was limited (37 \%) [15]. The published evidence is limited to a few small case series. Some of these use a combination of intravenous and nebulised antibiotics [16], others use a combination of nebulised antibiotics [17] and others a single nebulised antibiotic [18]. We report two children in whom new isolates of $\mathrm{BCC}$ have been successfully eradicated using the same combination of intravenous (IV) and inhaled antibiotics. These are the only two cases of attempted BCC eradication at our centre in the last eight years.

\section{Case presentations Child 1}

A 14 year old boy with CF (homozygous Phe508del) presented with a 2 week history of a wet cough productive of green sputum. His lung function remained stable $\left(\mathrm{FEV}_{1} 90 \%\right)$ and clinical examination was unremarkable. He was known to be chronically infected with Staphylococcus aureus but was free from Pseudomonas aeruginosa (last isolate 34 months previously) and had never grown $\mathrm{BCC}$. His treatment included nebulised dornase alfa but no nebulised antibiotics. The sputum culture from this presentation isolated BCC, Staphylococcus aureus, and Haemophilus influenza. Table 1 shows the antibiotic sensitivities. The BCC isolate was sent to the National Reference Laboratory where recA sequencing confirmed its identity as Burkholderia cepacia. The antibiotic sensitivities are given in Table 1. Five weeks after the first isolate, flexible bronchoscopy with single aliquot bronchoalveolar lavage samples (FB-BAL) from six lobes (including the lingula lobe) was performed to see if the organism had spontaneously cleared. BCC was isolated from all the sampled lobes. A 2 week eradication regimen was planned using intravenous (IV) tobramycin (10 $\mathrm{mg} / \mathrm{kg}$ once daily), ceftazidime (50 $\mathrm{mg} / \mathrm{kg}$ three times daily), and temocillin ( $2 \mathrm{~g}$ twice daily) followed by 3 months of nebulised meropenem ( $250 \mathrm{mg}$ twice daily). The IV antibiotics were administered in hospital without any problems. Trough serum tobramycin concentrations were $<1 \mathrm{mg} / \mathrm{L}$ when measured on day 2 and day 8 of treatment. Renal and liver functions were also within normal limits. Unfortunately, the patient could not tolerate the nebulised meropenem due to the taste. He was therefore prescribed 3 months of inhaled tobramycin. The possibility of using either a nebulised or a dry powder (TIP) formulation was discussed with the patient who chose the latter. The patient passed his trial of TIP and treatment was commenced (112 mg twice daily) the day after his IV antibiotics had finished. The family reported excellent adherence with the 3 months of treatment. All subsequent microbiology samples have been negative for BCC. These have included four sputum cultures whilst still on TIP, FB-BAL samples taken 1 month after the end of the eradication course and three subsequent cough swabs. The last sample was 13 months after the first $\mathrm{BCC}$ isolate.

\section{Child 2}

Four weeks after the above child first isolated BCC, a 6 year old girl with CF (homozygous Phe508del) also isolated BCC from a cough swab after a four week history of cough and shortness of breath. She had isolated Pseudomonas aeruginosa on two previous occasions (latest 20 months ago) and was receiving nebulised dornase alpha but not nebulised antibiotics. The BCC isolate was sent to the National Reference Laboratory where gryB cluster analysis confirmed its identity as Burkholderia gladioli. The antibiotic sensitivities are given in Table 1. FB-BAL was performed 4 weeks after the positive culture to check if it had spontaneously cleared but BCC was isolated from all six sampled lobes. She completed 2 weeks of IV tobramycin $(10 \mathrm{mg} / \mathrm{kg}$ once daily), ceftazadime (50 $\mathrm{mg} / \mathrm{kg}$ three times daily) and temocillin ( $1 \mathrm{~g}$ twice daily). Trough serum tobramycin concentrations were $<1 \mathrm{mg} / \mathrm{L}$ when measured on day 2 and day 8 of treatment. Renal and liver function were also within normal limits. As she had previously struggled to tolerate the taste of nebulised treatments

Table 1 Antibiotic sensitivities of the two BCC isolates

\begin{tabular}{|c|c|c|c|c|c|c|c|c|c|c|}
\hline & Ceftaz & Tazocin & Cipro & Gent & Tobra & Amikacin & Mero & Colistin & Aztreo & Temo \\
\hline Child 1 & $\mathrm{~S}$ & $S$ & 1 & $R$ & $R$ & $R$ & $S$ & $\mathrm{R}$ & 1 & $\mathrm{~S}$ \\
\hline Child 2 & S & R & । & । & I & $R$ & S & $R$ & R & S \\
\hline
\end{tabular}

Ceftaz ceftazidime; Cipro ciprofloxacin; Gent gentamicin; Tobra tobramycin; Mero meropenem; Aztreo aztreonam; Temo temocillin; S sensitive; I intermediate; $R$ resistant 
we did not try nebulised meropenem and went straight for 3 months of nebulised tobramycin (300 mg twice daily). This was started on the day the IV antibiotics finished. She tolerated this well and the family reported excellent adherence. During this time her lung function and clinical status remained stable. All subsequent microbiology samples have been negative for BCC. This has included four cough swabs cultures whilst still on nebulised tobramycin, FB-BAL samples taken 1 month after the eradication course finished and six subsequent cough swabs. The last sample was 12 months post first $\mathrm{BCC}$ isolate.

\section{Discussion}

We report two children with $\mathrm{CF}$ in whom new isolates of BCC were successfully eradicated using the same combination of intravenous and inhaled antibiotics. There is a paucity of evidence to inform practice on the eradication of BCC and we believe that these are the first two isolates successfully treated and reported in children. A Cochrane review concluded that there is "an extreme lack of evidence in this area of treatment management for people with cystic fibrosis" [13]. Although this report adds to the available evidence there is still an urgent need for multicentre randomised controlled trials to investigate antibiotic regimens for the eradication of BCC.

The $\mathrm{BCC}$ isolates in these children were identified as Burkholderia cepacia and Burkholderia gladioli. The progression of Burkholderia cepacia infection and its detrimental effect on morbidity and mortality is well established [11]. The clinical significance of Burkholderia gladioli infection in patients with $\mathrm{CF}$ is slightly more controversial as infections can be transient and prevalence of chronic infection is relatively low [19]. However, there is evidence that if chronic infection does develop there is associated morbidity both pre and post-transplant [20,21]. In these children we checked for spontaneous clearance by performing FB-BAL four/five weeks after the initial isolate. In both, BCC was identified in all six of the sampled lobes excluding this possibility. We were equally thorough in our assessment of the success of eradication. This included FB-BAL one month after eradication had completed in addition to regular respiratory microbiology samples during and after treatment.

\section{Conclusions}

In conclusion, new isolates of BCC can be eradicated in children with CF. This report identifies one possible eradication regimen using three IV antibiotics and one nebulised antibiotic. More research is required to establish which eradication regimen is the best for new isolates of BCC.

\section{Ethics and informed consent}

Ethical approval was not required for this article as case reports are not research. Written informed consent was obtained from the parents for publication of these case reports. A copy of the written consent is available for review by the Editor of this journal.

\section{Abbreviations \\ BCC: Burkholderia cepacia complex; CF: cystic fibrosis; FB-BAL: flexible bronchoscopy with bronchoalveolar lavage; IV: intravenous; TIP: tobramycin inhalation powder.}

Competing interests

None of the authors have any competing interests relevant to this article.

Authors' contributions

FG and WL were the patients CF clinicians. They devised the article and edited the manuscript. HK wrote the first draft and subsequent versions. All authors have seen and approved the final version of the manuscript.

\section{Funding}

No funding was received for this article.

Received: 6 November 2015 Accepted: 15 February 2016

Published online: 28 March 2016

References

1. Mahenthiralingam E, Urban TA, Goldberg JB. The multifarious, multireplicon Burkholderia cepacia complex. Nat Rev Microbiol. 2005;3:144-56.

2. Vanlaere E, Lipuma JJ, Baldwin A, Henry D, De Brandt E, Mahenthiralingam E, et al. Burkholderia latens sp. nov., Burkholderia diffusa sp. nov., Burkholderia arboris sp. nov., Burkholderia seminalis sp. nov. and Burkholderia metallica sp. nov., novel species within the Burkholderia cepacia complex. Int J Syst Evol Microbiol. 2008;58(Pt 7):1580-90.

3. Drevinek $P$, Mahenthiralingam E. Burkholderia cenocepacia in cystic fibrosis: epidemiology and molecular mechanisms of virulence. Clin Microbiol Infect. 2010;16:821-30.

4. Ledson MJ, Gallagher MJ, Jackson M, Hart CA, Walshaw MJ. Outcome of Burkholderia cepacia colonisation in an adult cystic fibrosis centre. Thorax. 2002;57:142-5.

5. Frangolias DD, Mahenthiralingam E, Rae S, Raboud JM, Davidson AG, Wittmann R, et al. Burkholderia cepacia in cystic fibrosis. Variable disease course. Am J Respir Crit Care Med. 1999;160(5 Pt 1):1572-7.

6. Jones AM, Dodd ME, Govan JRW, Barcus V, Doherty CJ, Morris J, et al. Burkholderia cenocepacia and Burkholderia multivorans: influence on survival in cystic fibrosis. Thorax. 2004;59:948-51.

7. Govan JR, Brown PH, Maddison J, Doherty CJ, Nelson JW, Dodd M, et al. Evidence for transmission of Pseudomonas cepacia by social contact in cystic fibrosis. Lancet Lond Engl. 1993;342:15-9.

8. Isles A, Maclusky I, Corey M, Gold R, Prober C, Fleming P, et al. Pseudomonas cepacia infection in cystic fibrosis: an emerging problem. J Pediatr. 1984;104:206-10.

9. De Soyza A, Meachery G, Hester KLM, Nicholson A, Parry G, Tocewicz K, et al. Lung transplantation for patients with cystic fibrosis and Burkholderia cepacia complex infection: a single-center experience. J Heart Lung Transplant Off Publ Int Soc Heart Transplant. 2010;29:1395-404.

10. UK Cystic Fibrosis Registry, 2014 Annual Data Report. Published August 2015 by the CF Trust Available at: http://www.cysticfibrosis.org.uk/media/ 1596846/RegistryReport2014.pdf

11. Govan JRW, Brown AR, Jones AM. Evolving epidemiology of Pseudomonas aeruginosa and the Burkholderia cepacia complex in cystic fibrosis lung infection. Future Microbiol. 2007:2:153-64.

12. Horsley A, Jones AM. Antibiotic treatment for Burkholderia cepacia complex in people with cystic fibrosis experiencing a pulmonary exacerbation. Cochrane Database Syst Rev. 2012;10:CD009529.

13. Regan $\mathrm{KH}$, Bhatt J. Eradication therapy for Burkholderia cepacia complex in people with cystic fibrosis. Cochrane Database Syst Rev. 2014;10:CD009876.

14. Aaron SD, Ferris W, Henry DA, Speert DP, Macdonald NE. Multiple combination bactericidal antibiotic testing for patients with cystic 
fibrosis infected with Burkholderia cepacia. Am J Respir Crit Care Med. 2000;161(4 Pt 1):1206-12.

15. Horsley A, Webb K, Bright-Thomas R, Govan J, Jones A. Can early Burkholderia cepacia complex infection in cystic fibrosis be eradicated with antibiotic therapy? Front Cell Infect Microbiol. 2011;1:18.

16. Etherington C, Peckham DG, Conway SP, Denton M. Burkholderia cepacia complex infection in adult patients with cystic fibrosis-is early eradication possible? J Cyst Fibros. 2003;2:220-1.

17. Middleton PG, Kidd TJ, Williams B. Combination aerosol therapy to treat Burkholderia cepacia complex. Eur Respir J. 2005;26:305-8.

18. Iglesias A, Artiles I, Cabanillas JJ, Alvarez-Sala R, Prados C. Eradication of Burkholderia cepacia Using Inhaled Aztreonam Lysine in Two Patients with Bronchiectasis. Case Rep Pulmonol. 2014;2014:192146.

19. Jones AM, Dodd ME, Webb AK. Burkholderia cepacia: current clinical issues, environmental controversies and ethical dilemmas. Eur Respir J. 2001;17:295-301.

20. Jones AM, Stanbridge TN, Isalska BJ, Dodd ME, Webb AK. Burkholderia gladioli: recurrent abscesses in a patient with cystic fibrosis. J Infect. 2001:42:69-71

21. Kennedy MP, Coakley RD, Donaldson SH, Aris RM, Hohneker K, Wedd JP, et al. Burkholderia gladioli: five year experience in a cystic fibrosis and lung transplantation center. J Cyst Fibros Off J Eur Cyst Fibros Soc. 2007:6:267-73.

Submit your next manuscript to BioMed Central and we will help you at every step:

- We accept pre-submission inquiries

- Our selector tool helps you to find the most relevant journal

- We provide round the clock customer support

- Convenient online submission

- Thorough peer review

- Inclusion in PubMed and all major indexing services

- Maximum visibility for your research

Submit your manuscript at www.biomedcentral.com/submit
Biomed Central 